\title{
PENGGUNAAN FUNGSI PELENGKAP PADA KALIMAT DALAM TRACT MEI 1968
}

\author{
Nokiamy Sesena Tamba ${ }^{1}$, Myrna Laksman-Huntley ${ }^{2}$ \\ ${ }^{1,2}$ Program Studi Prancis, Fakultas Ilmu Pengetahuan Budaya Universitas Indonesia \\ nokiamy.sesena@alumni.ui.ac.id \\ laksman@ui.ac.id
}

\begin{abstract}
Tract as a communication platform to call people to participate in demonstrations is still used by the French until 2019 in the Yellow Vest Movement. This proves the important usage of the track in France. The most important movement in French history that involves the utilization of tract was in Mai 68. By using it, the movement initiated by students of the University of Nanterre (May, 3rd 1968) was able to invite workers to join them on May 13 1968. However, it has a disadvantage due to paper usage: spatial limitations for the transmission of information. Therefore, it is necessary to pay attention to the choice of words, phrases, clauses, sentences, and presentations. Use qualitative methods and literature study; this article describes the utilization of the function accessory in the tracts on May 13 68, based on the sentence structure theory by Le Querler (1994). In the tract, variations of function accessories are presented according to the amount of paper used and to the freedom of presentation of the sentence by the creator. As a result, its utilization and presentation in the tract help the various groups involved on May 13, 1968, to gain a better understanding of the reasons and objectives to be carried out in the movement.
\end{abstract}

Keywords: Effect of the spatial limitation; Fonction accessoire; The call for movement; Tracts May 68.

\section{PENDAHULAN}

Gilets Jaunes (rompi kuning) adalah sebuah gerakan yang terjadi akibat akumulasi kekecewaan masyarakat terhadap kebijakan-kebijakan ekonomi yang dibuat pada saat pemerintahan Emmanuel Macron (Fourquet dan Manternach, 2018). Menurut Duval (2018), gerakan ini awalnya dimulai pada tanggal 17 November dalam upaya menuntut pemerintah atas kenaikan pajak bahan bakar di Prancis. Akan tetapi, tuntutan tersebut meluas kepada semua kebijakan pemerintahan Macron yang dirasa memberatkan masyarakat kalangan menengah ke bawah. Gerakan tersebut masih berlanjut hingga artikel ini dituliskan walaupun alasan gerakan dirasa telah berubah («Après un acte 16 peu mobilisateur, les gilets jaunes misent sur un regain le 16 mars », 2019)
«Qui paye les tracts des gilets jaunes ?» (2018) berpendapat pada gerakan ini tract (selebaran) telah disebar secara cetak sejak tanggal 11 November 2018 untuk memanggil masyarakat agar ikut berpatisipasi pada gerakan Rompi Kuning pada 17 November 2018. Selain itu, terdapat situs yang mengatasnamakan diri sebagai gilets jaunes touluse yang menyebarkan tract secara daring dan memperbolehkan siapapun untuk mencetaknya jika dibutuhkan («4 - 5 - 6 février 2019 - blocage national et appel à la grève générale », 2019). Oleh sebab itu, penggunaan tract masih dapat dikatakan penting dan juga mematahkan argumen dari Contamin (2008) mengenai tract sebagai alat komunikasi demonstrasi yang tidak akan digunakan oleh masyarakat Prancis akibat kemajuan teknologi karena hal tersebut justru membantu penyebaran tract. 


\section{2 | JURNAL ILMU BUDAYA}

Volume 8, Nomor 1, Juni 2020
Penggunaan tract yang paling penting tercatat dalam sejarah Prancis adalah pada saat gerakan Mei 68 Prancis (Service de l'Histoire de la France, 1987). Gerakan yang dimulai oleh para mahasiswa di Universitas Nanterre ini pada tanggal 3 Mei 1968 (Guilhaumou, 2010) berhasil mengajak kelompok lain di masyarakat, yaitu para pekerja pada tanggal 13 Mei 1968 (Cohen, 2008). Gerakan terus membesar dan diikuti berbagai kelompok masyarakat, sehingga mampu membuat Pemerintah Prancis bergerak cepat dalam pembuatan undang-undang. Oleh sebab itu, Mei 68 menjadi salah satu peristiwa penting dalam sejarah Prancis yang mengubah tatanan hidup masyarakatnya, seperti pendidikan (Sejatmiko, 2013), gender (Ismoyo, 2017), bahkan arsitektur (Doucet, 2019). Gerakan tersebut bahkan dijadikan pembanding dengan gerakangerakan yang terjadi saat ini seperti yang dilakukan Žižek (2018).

Hal yang menarik dari penggunaan tract di gerakan tersebut adalah ketiadaan akses internet dan komputer untuk organisator dan masyarakat, sehingga tract menjadi sumber informasi yang sangat penting untuk menghimpun masayarakat untuk terlibat dalam suatu gerakan (Contamin, 2008). Walaupun demikian, tract memiliki kekurangan sebagai alat komunikasi karena ukuran media yang digunakan (Carbonnier dalam Tamba \& Laksman-Huntley, 2019). Oleh sebab itu, isi tract menjadi penting dalam penyampaian komunikasi dari organisator gerakan kepada masyarakat, termasuk kalimat.

Kajian kalimat berbahasa Prancis telah banyak dilakukan seperti pada penelitian Zouadi (2017), Aprilianty (2015), Ratna (2016), Arisyana dan Widodo (2017), serta Rossari (2018). Penelitian-penelitian tersebut menunjukkan keunikan tata bahasa, pemilihan kata dan klausa dalam kalimat berbahasa Prancis mampu mengekspresikan emosi yang dipengaruhi sebuah konteks. Oleh sebab itu, kalimat menjadi hal penting dalam komunikasi di bahasa Prancis.

Sementara itu, Demonet, dkk (1975) telah melakukan kajian lingustik dengan korpus tract Mei 1968. Ditemukan kata pouvoir adalah kata tersering yang muncul pada tract selama Mei 68 di Prancis. Sementara itu, secara historis dan kebudayaaan, Ball (2010) menyimpulkan keinginan revolusi masyarakat Prancis dalam tract-tract pada periode tersebut. Penelitian yang serupa dengan korpus tract Mai 68 dilakukan oleh Karim, dkk (2019) yang meneliti pamflet sosialisasi pelestarian lingkungan di Kabupaten Wakatobi menggunakan kajian pragmatik berupa pranggapan. Melalui penelitiannya, ditemukan bahwa penyusunan pamflet berbeda-beda menyesuaikan pengetahuan bersama, partisipan, dan konteks situasi. Selain itu, terdapat penelitian yang telah dilakukan penulis (Tamba \& LaksmanHuntley, 2019) mengenai struktur kalimat pada salah satu tract 13 Mai 1968 berdasarkan badan tract, yaitu titre (judul) dan intertitres et les paragraphes (antarjudul dan paragraf) dengan teori Le Querler (1994). Penulis berfokus pada penggunaan fungsi pelengkap dalam kalimat tunggal dan penghilangan unsur kalimat. Berdasarkan analisis tersebut, penulis mengungkapkan kemungkinan bahwa kalimat-kalimat dalam tract merupakan kalimat yang singkat dan mudah dibaca. Fungsi pelengkap dalam bagian analisis menjadi salah satu unsur terpenting dalam struktur kalimat yang memungkinkan terjadinya penyusunan pesan di media tract yang terbatas. Selain itu, penelitian terdahulu menggunakan satu korpus tract yang berakhir pada kesimpulan berupa kemungkinan dan kecenderungan struktur-struktur kalimat dalam tract. Oleh sebab itu, penelitian ini akan membahas lebih lanjut salah satu 


\section{3 | JURNAL ILMU BUDAYA}

Volume 8, Nomor 1, Juni 2020
E-ISSN: 2621-5101

P-ISSN:2354-7294 bagian dalam struktur kalimat tract, yaitu fungsi pelengkap dan bagaimana penyajiannya dalam kalimat-kalimat tract seruan aksi 13 Mei 1968 lain yang berhasil mengajak kelompok lain, yaitu buruh, untuk berdemonstrasi bersama mahasiswa.

\section{METODE}

Penelitian ini dilakukan secara kualitatif dengan menggunakan studi kepustakaan untuk pengumpulan data, dengan berfokus pada kajian sintaksis, yaitu penggunaan fungsi pelengkap pada kalimat oleh Le Querler (1994) untuk memperlihatkan cara gagasan disampaikan oleh pembuat tract untuk memersuasi pembaca agar hadir pada waktu dan tempat yang telah ditentukan pada aksi 13 Mei 1968. Dengan demikian, penelitian ini berfokus pada tract tanpa gambar pelengkap, karena gambar di sekitar tulisan dapat mengandung pesan baru yang merupakan wilayah kajian intersemiotik (Liu dan O'Halloran, 2009).

Sumber data yang digunakan dalam penelitian ini adalah dua tract seruan aksi 13 Mei 1968 yang tidak memiliki konten gambar yang disetujui oleh lebih dari lima serikat dan berasal dari dua sumber daring yang berbeda, yaitu Tract 1 (1 halaman) dari koleksi pribadi seorang tokoh politik Prancis, Jean Réne Chauvin (2017) yang diakses dari https://chsprod.hypotheses.org/jean-renechauvin-parcours-dun-militant/les-annees68-et-apres/tracts-printemps-1968 dan Tract 2 (2 halaman) dari koleksi pribadi seorang pengamat tract Mei 68, Ian Thompson (2016) yang diakses dari https://mai68inenglish.com/2016/08/20/tra $c t$-the-organisations-of-the-u-n-e-f-u-g-ethe-s-n-e-sup-the-c-g-t-the-c-f-d-t-and-thef-e-n-make-the-following-call-12-may1968-unef-snesup-cgt-cfdt-fen/.
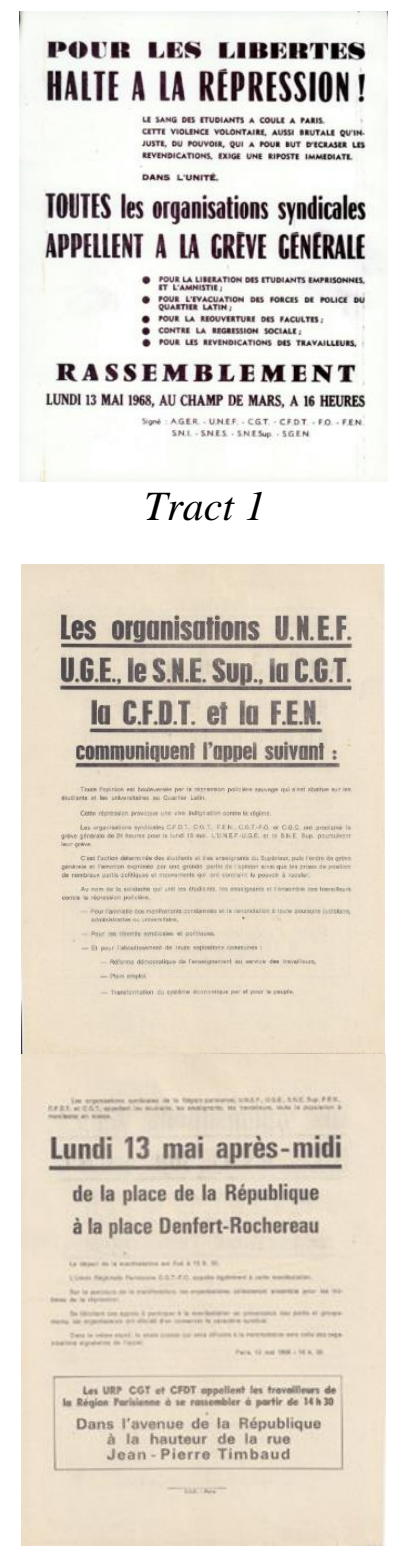

Tract 2

Melalui paparan tentang tahapan penyusunan tract dalam "Comment rediger un tract" (1990), pembuat tract harus mengetahui hal-hal yang berkaitan dengan pesan yang ingin disampaikan sebelum menyiapkan tract, seperti tujuan, konteks, isi, dan pemilihan, serta penyajian kata, frasa, atau kalimat. Hal tersebut penting agar tidak menimbulkan ambiguitas pesan kepada pembaca. Oleh sebab itu, penting untuk pembuat tract memerhatikan tiga bagian dalam badan 


\section{4 | JURNAL ILMU BUDAYA}

Volume 8, Nomor 1, Juni 2020
E-ISSN: 2621-5101

P-ISSN:2354-7294 tract, yaitu bagian titre (judul), intertitres et les paragraphes (antarjudul dan paragraf), dan conclusion (kesimpulan). Titre biasanya berada di bagian awal dan menjadi pembuka suatu tract yang diharapkan menarik minat pembaca tract untuk melanjutkan pembacaan tract. Pada bagian intertitres et les paragraphes, pembuat tract dapat menempatkan pesanpesan utama dan penjelasan yang ingin disampaikan pada pembaca tract. Perbedaan antara intertitres dan les paragraphes adalah intertitres memiliki ukuran huruf yang sama dengan judul tract, sedangkan les paragraphes tidak. Oleh sebab itu, tipografi, jarak spasi, dan juga kekosongan ruang tract perlu diperhatikan agar pesan dapat dibaca dengan mudah. Berikutnya adalah bagian la signature (tanda tangan) yang berisi identitas organisasi yang membuat dan menyetujui tract agar dapat dihubungi oleh pembaca jika mereka membutuhkan informasi tambahan.

\section{Le Querler}

Nicole Le Querler (1994) yang berjudul Précis de syntaxe française. Melalui buku tersebut, Le Querler (1994) berpendapat bahwa kalimat terdiri atas kumpulan frasa fungsional dan berpusat pada frasa verba yang disebut pivot (pusat). Dengan demikian, dalam analisis struktur kalimat, perlu diperhatikan fungsi frasa pada kalimat. Le Querler (1994) lebih lanjut membagi fungsi frasa menjadi dua, yaitu fungsi primer dan fungsi sekunder.

Fungsi primer adalah fungsi milik frasafrasa yang secara langsung berhubungan pada verba utama yang menjadi pivot. Berdasarkan fungsinya pada struktur kalimat, fungsi primer terdiri atas fonction essentielle (fungsi esensial) yang wajib hadir agar struktur kalimat gramaticale dan fonction accessoire (fungsi pelengkap) yang keberadaannya opsoinal namun memberikan makna tambahan pada kalimat. Fungsi utama esensial terdiri atas subjek, complement d'objet (pelengkap objek), complement d'agent, complement $d u$ presentatif, attribut du sujet, attribut $d u$ $C O D$, dan locatif; sedangkan fungsi utama pelengkap terdiri atas complement circonstencielle.

Fungsi sekunder adalah fungsi milik frasa-frasa yang tidak berhubungan secara langsung dengan pivot: verba utama. Fungsi sekunder hanya memiliki fungsi pelengkap. Menurut Le Querler (1994), yang termasuk fungsi sekunder pelengkap adalah expansion $d u$ nom (perluasan nomina), expansion $d u$ pronom (perluasan pronomina), expansion de l'adjectif (perluasan adjektif), dan expansion de l'adverb (perluasan adverbia).

\section{Contoh fungsi primer dan sekunder:}

\begin{tabular}{|l|l|l|l|l|}
\hline Pierre & déteste & $\begin{array}{l}\text { la } \\
\text { fille }\end{array}$ & qui & porte \\
\hline Pierre & membenci & gadis & yang & memakai \\
\hline la robe & bleue & & & \\
\hline gaun & biru \\
\hline
\end{tabular}

\begin{tabular}{|l|l|l|}
\hline \multicolumn{1}{|c|}{ Séquence } & \multicolumn{1}{|c|}{ Catégorie } & \multicolumn{1}{|c|}{ Fonction } \\
\hline Pierre & $\begin{array}{l}\text { Frasa nomina } \\
\text { Frasa Verbal }\end{array}$ & Subjek \\
déteste & Frasa nomina \\
$\begin{array}{l}\text { la fille qui } \\
\text { porte la robe } \\
\text { bleue }\end{array}$ & & $\begin{array}{l}\text { Complément } \\
\text { Objet Direct } \\
\text { (COD) }\end{array}$ \\
\hline
\end{tabular}

Tabel di atas menunjukkan fungsi primer (subjek dan COD) dalam kalimat. Frasa subordinal rélative: qui porte la robe bleue yang merupakan expansion du nom dari la fille merupakan fungsi sekunder. Tanpa bagian ini, kalimat tetap baik secara sintaksis. Namun, secara semantis, pembaca dapat bertanya «gadis yang mana ? ». 


\section{5 | JURNAL ILMU BUDAYA}

Volume 8, Nomor 1, Juni 2020
E-ISSN: 2621-5101

P-ISSN:2354-7294

\section{HASIL DAN PEMBAHASAN}

Melalui struktur badan tract, terlihat bahwa kedua tract menggunakan judul berupa panggilan untuk melakukan demonstrasi dan pemogokan massal. Akan tetapi, tract 1 tidak menyatakan secara langsung menyatakan panggilan untuk demonstrasi dan pemogokan massal, tetapi imbauan untuk menghentikan represi dan mendapatkan kebebasan. Pada bagian intertitres et les paragraphes yang berisi pesan-pesan dari tract, kalimat dalam dua tract secara umum menyiratkan adanya masalah yang sedang terjadi di masyarakat dan menjadi pemicu dari pembuatan tract, serta panggilan untuk melakukan demonstrasi dan pemogokan massal yang merupakan cerminan tujuan pembuatan tract. Akan tetapi, tract 2 yang berhalaman dua memiliki informasi tambahan yang tidak dimiliki oleh tract 1 , dan dinyatakan melalui tiga kalimat. Tiga kalimat tersebut berisi informasi mengenai hal-hal yang akan dilakukan selama demonstrasi dan pemogokan. Untuk mempermudah penyajian tabel pembahasan mengenai les intertitres et les paragraphes, maka kalimat-kalimat akan dikelompokkan berdasarkan informasi yang tersirat menjadi «Masalah», «Panggilan Demonstrasi », serta «Hal yang harus diperhatikan selama demonstrasi » yang hanya berada pada tract 3 di tabel terlampir. Pada bagian signature, tanda organisasi yang menyetujui pembuatan tract 1 ditemukan di bagan akhir. Sementara itu, signature pada tract 2 menyatu dengan intertitres et les paragraphes. Oleh sebab itu, tidak ada pembahasan lebih lanjut pada bagian signature.

Kedua tract korpus menggunakan strategi penyajian frasa dan kalimat yang serupa, yaitu dengan ukuran huruf yang cukup besar. Selain informasi tambahan di tract 2, perbedaan jumlah halaman pada kedua korpus mengakibatkan perbedaan jumlah kalimat pada dua tract yang cukup besar. Tract 1 yang memiliki satu halaman, terdiri atas 5 kalimat (4 tunggal dan 1 majemuk), sedangkan tract 2 memiliki 14 kalimat (9 tunggal dan 5 majemuk). Akan tetapi, kedua tract memiliki persamaan dalam penyajian, terutama penggunaan fungsi pelengkap yang cukup banyak. Fungsi pelengkap dalam kalimat dapat ditemukan pada kalimat tunggal dan bullet list (daftar berpoin). Selain itu, kedua tract juga menunjukkan adanya penghilangan unsur kalimat pada kalimat yang memiliki fungsi pelengkap di daftar berpoin.

\section{Fungsi Pelengkap di bagian Titre}

Dua tract yang menjadi korpus menggunakan kalimat tunggal sebagai titre dari tract yang menggunakan fungsi pelengkap.

\section{Tract 1}

$\begin{array}{llllll}\text { Pour } & \text { les } & \text { libertés, } & \text { halte } & \text { à } & \text { la } \\ \text { Untuk } & \text { art. } & \text { kebebasan, } & \text { hentikan } & \text { pada } & \text { art. } \\ & \text { def. } & \text { (jamak) } & & & \text { def. } \\ & \text { jamak } & & & \text { f. }\end{array}$

répression!

represi!

\section{Tract 2}

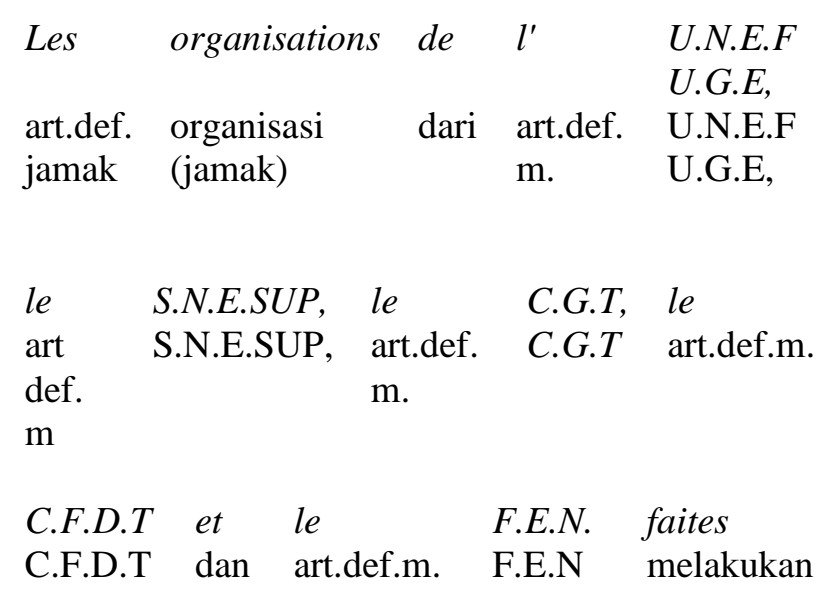




\section{6 | JURNAL ILMU BUDAYA}

Volume 8, Nomor 1, Juni 2020 $\begin{array}{lll}l^{\prime} & \text { appel } & \text { suivant. } \\ \text { art.def.m. } & \text { panggilan } & \text { lanjutan. }\end{array}$

Tract 1 menggunakan kalimat imperative sebagai titre. Oleh sebab itu, kalimat cenderung lebih pendek karena tidak memerlukan subjek. Pada kalimat tersebut, halte dilengkapi dengan frasa nomina preposisi à la répression (COI : fungsi primer dan esensial). Fungsi pelengkap ditandai oleh keberadaan frasa nomina preposisi pour les libertés yang merupakan C.C de but (fungsi primer pelengkap). Berbeda dengan tract 1 , tract 2 menggunakan kalimat tunggal afirmatif. Pivot kalimat adalah verba faire yang merupakan verba transitif, sehingga membutuhkan COD: l'appel suivant. Keberadaan fungsi pelengkap pada kalimat terletak pada frasa yang menempati bagian subjek, yaitu frasa nomina les organisations. Terdapat expansion du nom dari frasa tersebut : nama-nama dari enam organisasi pembuat tract.

Penggunaan kalimat tunggal menunjukkan bahwa judul cenderung singkat dan hanya memiliki satu inti pesan utama yang mampu menarik pembaca tract. Walaupun demikian, pembuat tract tetap dapat menyisipkan informasi tambahan yang dirasa mampu menarik perhatian pembaca. Hal ini terlihat melalui keberadaan fungsi pelengkap. Pada tract 1 , pembuat tract dapat menyisipkan tujuan dari aksi 13 Mei 1968 dengan C.C de but, sedangkan tract 2 menyisipkan informasi mengenai nama-nama dari organisasi yang ikut serta dalam aksi pemanggilan gerakan ini.

\section{Fungsi Pelengkap di Kalimat Tunggal} (Intertitres et Les Paragraphes)

Kalimat tunggal pada umumnya singkat dan hanya mengandung satu informasi saja. Akan tetapi, dengan adanya frasa-frasa yang menempati fungsi pelengkap, kalimat dapat menambahkan informasi tambahan. Hal ini terlihat pada kedua tract yang menjadi korpus.

Le $\quad$ sang $\begin{array}{cc}\text { Tract 1 } \\ \text { des étudiants }\end{array}$

Art.def.m darah milik pelajar (jamak)

$\begin{array}{llll}a & \text { coulé } & \grave{a} & \text { Paris } \\ \text { kata kerja } & \text { p.passé } & \text { di } & \text { Paris } \\ \begin{array}{l}\text { bantu untuk } \\ \text { kala lampau }\end{array} & \text { mengalir } & & \\ \text { ald } & & & \end{array}$
$\mathbf{S}:$ Le sang des étudiants
$\mathbf{P}:$ a coulé

Locatif : à Paris.

Pada tract 1 , le sang des étudiants merupakan frasa nomina yang menempati posisi subjek yang berhubungan secara langsung dengan pivot kalimat : bentuk passé dari verba couler. Pivot pada kalimat ini merupakan verba intransitif, sehingga secara gramatikal dapat memenuhi syarat sebagai sebuah kalimat. Akan tetapi, ditemukan frasa nomina preposisi yang menempati fungsi pelengkap berisi informasi tempat, yaitu à Paris.

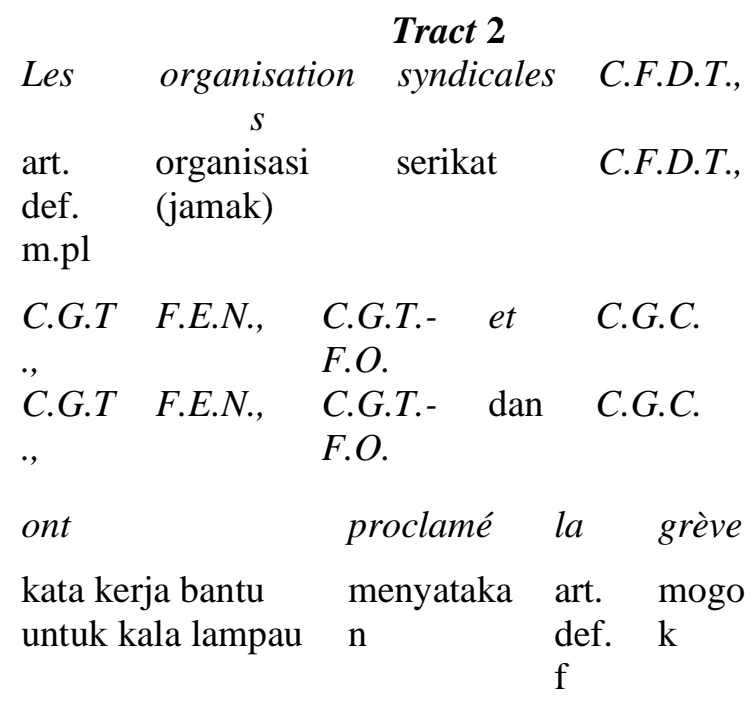


générale de 24 pour le lundi massal untuk 24 untuk art.def.m. Senin

13 mai.

13 Mei.

S : Les organisations syndicales C.F.D.T., C.G.T., F.E.N., C.G.T.-F.O. et C.G.C.

P : ont proclamé

COD : la grève générale de 24 heures

CC. de temps : pour le lundi 13 mai.

Hal yang serupa terjadi pada Tract 2 yang memiliki fungsi pelengkap C.C de temps pada kalimat tunggalnya. Pivot kalimat ini merupakan bentuk lampau dari verba transitif proclamer, yaitu ont proclame. Pivot tersebut didahului oleh frasa nomina les organisations syndicales dengan keterangan enam organisasi yang dimaksud menjadi subjek pada kalimat tersebut. Akibat penggunaan verba transitif tersebut, terdapat frasa nomina: la grève générale de 24 heures yang menempati fungsi COD. Dengan frasa-frasa yang menempati fungsi tersebut, kalimat telah lengkap dan tidak rumpang secara sintaksis. Akan tetapi, ditemukan frasa nomina preposisi yang menempati fungsi C.C de temps: pour le lundi 13 mai atau dengan kata lain fungsi primer pelengkap.

Melalui analisis dua kalimat tersebut, terlihat bahwa adanya tambahan informasi waktu atau tempat dengan menggunakan fungsi pelengkap dalam kalimat. Keberadaan fungsi pelengkap tersebut membantu pembaca memahami panggilan ini dengan jelas mengenai lokasi kejadian dan waktu panggilan. Hal ini sesuai dengan teori Le Querler (1994) yang menyatakan bahwa tanpa fungsi pelengkap tersebut, kalimat sebenarnya sudah utuh secari sintaksis. Akan tetapi, mereka memberikan informasi tambahan yang merupakan unsur semantik, sehingga kalimat tidak hanya utuh secara sintaksis namun juga dapat dimengerti dengan baik oleh pembaca.

\section{Penggunaan Bullet List (Daftar Berpoin) dan Penghilangan Unsur Kalimat}

Pada kedua korpus, ditemukan kalimat yang menggunakan daftar berpoin untuk menyajikan fungsi-fungsi pelengkapnya di bagian intertitres et les paragraphes.

\section{Tract 1}

$\begin{array}{lllll}\text { Dans } & l^{\prime} & \text { unité, } & \text { toutes } & \text { les } \\ \text { Dalam } & \begin{array}{l}\text { art. } \\ \text { def.f. }\end{array} & \text { persatuan } & \text { semua } & \begin{array}{l}\text { art. def. } \\ \text { jamak }\end{array}\end{array}$

organisations syndicales appellent organisasi serikat memanggil

(jamak)

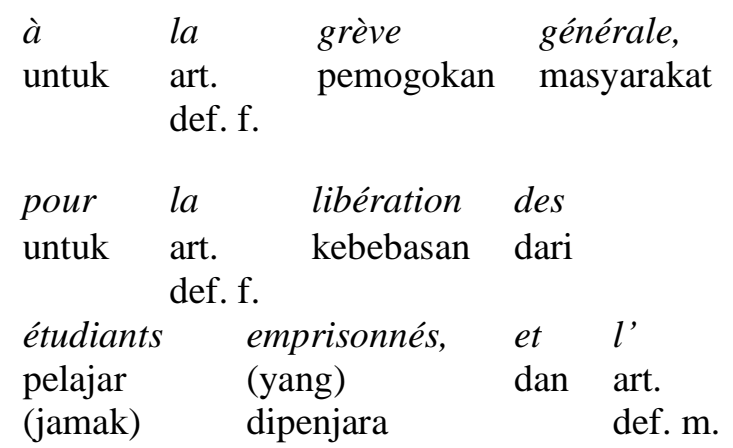

amnistie, pour l' évacuation amnesti, untuk art. evakuasi def. $\mathrm{f}$.

des forces de police du

dari tekanan milik polisi dari

Quartier Latin; pour la Quartier Latin; untuk art. def. f.

réouverture des facultés; contre pembukaan art.indef. fakultas melawan kembali jamak (jamak),

la régression sociale; pour les

art. regresi sosial untuk art.

def.f. def. 


\section{8 | JURNAL ILMU BUDAYA}

Volume 8, Nomor 1, Juni 2020 revendications des travailleurs.

tuntutan milik pekerja (jamak).

\section{C.C de manière : Dans l'unité,}

$\mathbf{S}:$ Toutes les organisations syndicales

$\mathbf{P}$ : appellent

$\mathrm{COI}$ : à la grève générale :

\section{C.C de but:}

- pour la libération des étudiants emprisonnés, et l'amnistie;

- pour l'évacuation des forces de police du Quartier Latin;

- pour la réouverture des facultés;

- contre la régression sociale;

- pour les revendications des travailleurs

Pada kalimat tunggal ini, terlihat bahwa frasa nomina preposisi dans l'unité yang merupakan C.C de manière mendahului frasa nomina yang menjadi subjek: toutes les organisations syndicales. Pivot dalam kalimat adalah konjugasi dari verba appeler yang merupakan verba transitif dan membutuhkan COI dan COD. Oleh sebab itu, ditemukan frasa nomina preposisi à la grève générale menempati fungsi COI. Akan tetapi, tidak ditemukan frasa yang menempati fungsi COD. Penulis mencurigai kemungkinan bahwa ini adalah kesalahan pembuat tract atau penarik perhatian pembaca untuk membuat pembaca sadar secara langsung bahwa COD tract tersebut ditujukan pada mereka: masyarakat Prancis. Kalimat dilanjutkan dengan 5 frasa nomina preposisi yang merupakan fungsi pelengkap : C.C de but dalam bentuk daftar berpoin pada kalimat ini, yaitu pour la libération des étudiants emprisonnés, et l'amnistie; pour l'évacuation des forces de police du
Quartier Latin; pour la réouverture des facultés; contre la régression sociale; pour les revendications les travailleurs.

Menurut Le Querler (1994), tanpa adanya frasa yang menempati fungsi pelengkap kalimat sudah utuh namun fungsi tersebut memberikan informasi baru dalam kalimat. Dengan kata lain, tanpa keberadaan fungsi pelengkap dalam kalimat ini (frasa-frasa yang menempati fungsi C.C de manière dan C.C de but), kalimat telah lengkap. Hal yang menarik adalah penyajian C.C de but dalam daftar berpoin di kalimat ini yang membuat pembaca tidak akan menyadari banyaknya unsur yang merupakan informasi tambahan dalam kalimat tunggal ini. Selain itu, penggunaan daftar berpoin ini membantu pembaca dalam membaca kalimat.

\section{Tract 2}

$\begin{array}{llllll}A u & \text { nom } & \text { de } & \text { la } & \text { solidarité } & \text { qui } \\ \text { Atas } & \text { nama } & \text { dari } & \begin{array}{l}\text { art. } \\ \text { déf.f. }\end{array} & \text { solidaritas } & \text { yang }\end{array}$

\begin{tabular}{|c|c|c|c|}
\hline $\begin{array}{l}\text { unit } \\
\text { menyatukan }\end{array}$ & $\begin{array}{l}\text { les } \\
\text { art. def. } \\
\text { jamak }\end{array}$ & $\begin{array}{l}\text { étudiants, } \\
\text { pelajar } \\
\text { (jamak) }\end{array}$ & $\begin{array}{l}\text { les } \\
\text { art. def } \\
\text { jamak }\end{array}$ \\
\hline enseignants & et & tous & les \\
\hline $\begin{array}{l}\text { pengajar } \\
\text { (jamak) }\end{array}$ & dan & semua & $\begin{array}{l}\text { art. def. } \\
\text { jamak }\end{array}$ \\
\hline $\begin{array}{l}\text { travailleurs } \\
\text { pekerja } \\
\text { (jamak) }\end{array}$ & $\begin{array}{l}\text { contre } \\
\text { melawan }\end{array}$ & $\begin{array}{l}\text { la } \\
\text { art. } \\
\text { déf. f. }\end{array}$ & $\begin{array}{l}\text { répression } \\
\text { represi }\end{array}$ \\
\hline $\begin{array}{l}\text { policière, } \\
\text { polisi, }\end{array}$ & $\begin{array}{l}\text { pour } \\
\text { untuk }\end{array}$ & $\begin{array}{l}l \\
\text { art. def. f. }\end{array}$ & $\begin{array}{l}\text { amnistie } \\
\text { amnesti }\end{array}$ \\
\hline $\begin{array}{ll}\text { des } & \text { ma } \\
\text { art. } & \text { den } \\
\text { indéf. } & \text { (jan } \\
\text { jamak } & \end{array}$ & $\begin{array}{l}\text { nifestants } \\
\text { nonstran } \\
\text { mak) }\end{array}$ & $\begin{array}{l}\text { condamnés } \\
\text { terhukum } \\
\text { (participe } \\
\text { passé) }\end{array}$ & $\begin{array}{ll}s & e t \\
& \text { dan }\end{array}$ \\
\hline
\end{tabular}




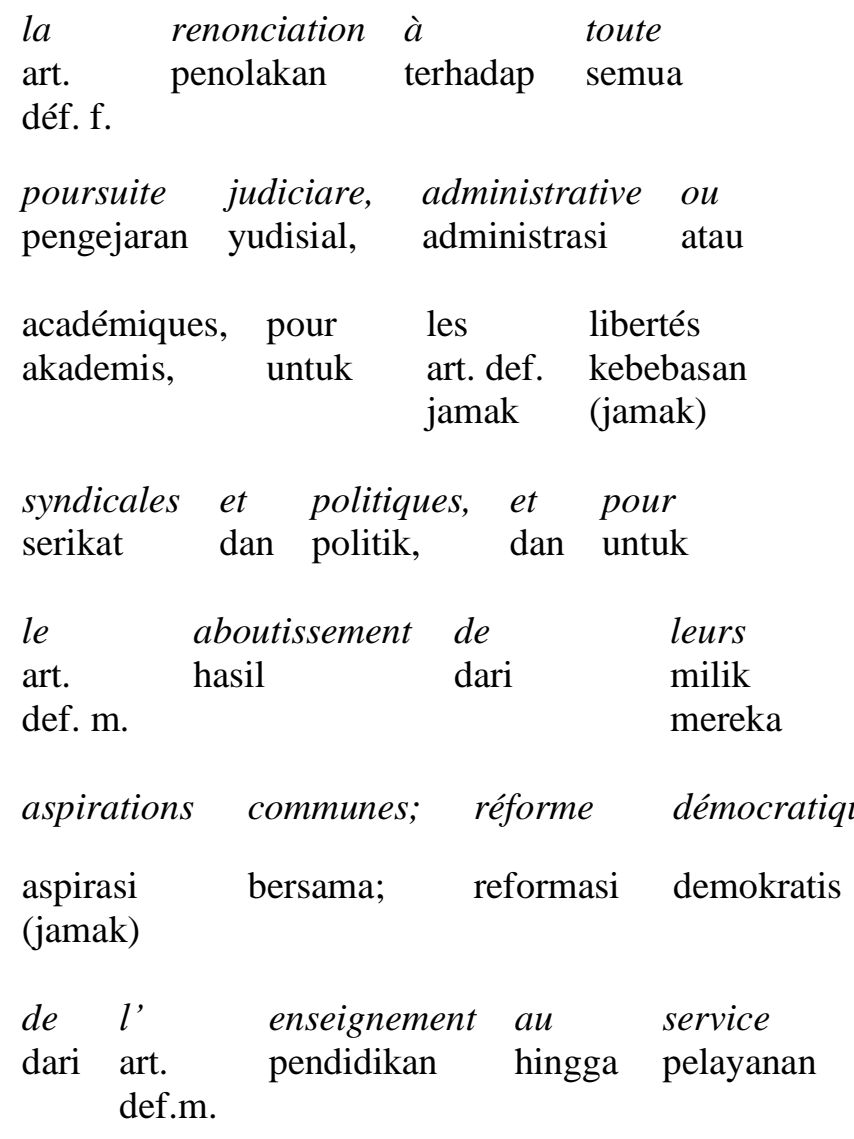

$\begin{array}{llll}\begin{array}{l}\text { des } \\ \text { art. indéf. }\end{array} & \begin{array}{l}\text { travailleurs, } \\ \text { pekerja } \\ \text { jamak }\end{array} & \begin{array}{l}\text { plein } \\ \text { (jamak), }\end{array} & \text { emploi, }\end{array}$

$\begin{array}{llll}\text { transformation } & d u & \text { système } & \begin{array}{l}\text { économique } \\ \text { ekonomis }\end{array} \\ \text { transformasi } & \text { art. } & \text { sistem } & \text { ekóf. m. }\end{array}$

$\begin{array}{lllll}\text { par } & \text { et } & \text { pour } & \text { le } & \text { peuple. } \\ \text { oleh } & \text { dan } & \text { untuk } & \begin{array}{l}\text { art. def. } \\ \text { m. }\end{array} & \end{array}$

CC. de manière : Au nom de la solidarité qui unit les étudiants, les enseignants et tous les travailleurs
$\mathbf{S}:-$
P : -
COD : contre la répression policière

\section{C.C de but :}

- pour l'amnistie des manifestants condamnés et la renonciation à toute poursuite judiciaire, administrative ou académiques,

- pour les libertés syndicales et politiques,

- et pour l'aboutissement de leurs aspirations communes ;

- Réforme démocratique de l'enseignement au service des travailleurs,

- plein emploi,

- transformation du système économique par et pour le peuple.

Penghilangan unsur kalimat juga uiterjadi pada kalimat yang menggunakan daftar berpoin untuk penyajian fungsi pelengkapnya di tract 2 ini. Pada kalimat majemuk subordinatif ini, diawali oleh frasa nomina preposisi Au nom de la solidarité qui unit les étudiants, les enseignants et tous les travailleurs yang menggunakan pronom rélative qui (penanda kalimat majemuk subordinatif) untuk mengikat informasi tambahan berupa penjelas mengenai au nom de la solidarité. Kalimat lalu dilanjutkan dengan frasa nomina preposisi contre la répression policière yang merupakan COD. Tidak ditemukan subjek ataupun pivot dalam kalimat. Jika melihat kalimat ini berada dalam tract panggilan untuk aksi 13 Mei, maka penulis mencurigai bahwa pivot dalam kalimat ini merupakan bentuk imperatif dari verba être : soyez.

Penggunaan daftar berpoin dalam kalimat ini menyatukan kumpulan frasa nomina preposisi yang merupakan fungsi pelengkap : C.C de but. Berdasarkan teori Le Querler (1994), tanpa adanya fungsi pelengkap tersebut kalimat tidak akan rumpang. Namun, keberadaan fungsi pelengkap menambah informasi pada suatu kalimat. Hal ini menunjukkan kemiripan 


\section{0 | JURNAL ILMU BUDAY}

Volume 8, Nomor 1, Juni 2020
E-ISSN: 2621-5101

P-ISSN:2354-7294 dengan kalimat pada tract 1 bahwa terdapat banyak unsur yang merupakan informasi tambahan dalam kalimat ini dan membantu pembacaan kalimat.

Melalui analisis tersebut, terlihat bahwa terjadi penghilangan unsur kalimat dan penggunaan daftar berpoin dalam satu kalimat pada setiap tract. Secara sintaksis, kalimat tersebut rumpang dan tidak lengkap. Akan tetapi, hal tersebut tidak membuat kalimat kehilangan makna atau dengan kata lain dapat dipahami secara semantik. Hal ini menimbulkan kecurigaan pada peneliti mengenai kemungkinan karena adanya kesalahan gramatikal pembuat tract atau sebuah strategi yang dilakukan agar pesan-pesan dapat disampaikan pada pembaca. Dalam hal ini, frasa-frasa berfungsi pelengkap yang berada dalam daftar berpoin.

\section{KESIMPULAN}

Pada dua tract seruan aksi 13 Mei 1968 yang menjadi korpus, dominasi kalimat tunggal ditemukan dalam setiap tract. Hal ini memperlihatkan bahwa tract umumnya menggunakan kalimat-kalimat yang mudah dibaca. Penggunaan fungsi pelengkap menjadi salah satu strategi dalam menghadapi keterbatasan tersebut. Oleh sebab itu, fungsi pelengkap dapat ditemukan pada judul, kalimat-kalimat tunggal di bagian intertitres et les paragraphes, dan bagian daftar berpoin. Selain itu, penghilangan unsur kalimat ditemukan pada kalimat yang menggunakan daftar berpoin dalam menyajikan fungsi pelengkap. Hal tersebut dilihat peneliti sebagai upaya untuk mengatasi keterbatasan ruang kertas dan memunculkan unsur terpenting dalam menyampaikan pesan.

Keseluruhan simpulan terkait erat dengan target pembaca tract seruan aksi dan kepentingan gerakan 13 Mei 1968. Penggunaan kalimat yang singkat namun mengandung banyak informasi yang mudah dibaca adalah sebuah strategi pembuat tract agar pembaca dari kelompok berbeda memahami gerakan hingga berpartisipasi pada aksi tersebut. Oleh sebab itu, pemilihan dan penyusunan kalimat pun memiliki ciri khas masingmasing. Akan tetapi, inti pesan tersebut sama, yaitu sebuah panggilan untuk melakukan aksi bersama dalam menuntut keadilan dalam masyarakat. Temuan yang diperoleh dari penggunaan fungsi pelengkap menunjukkan bahwa keterbatasan media dalam menyampaikan pesan dapat diatasi dengan strategi-strategi yang digunakan pada tract.

Penelitian ini menegaskan pentingnya pemilihan dan penyajian frasa atau kalimat dalam menyampaikan gagasan tertulis agar dapat dipahami oleh pembaca yang berasal dari berbagai kalangan dengan keterbatasan ruang kertas. Dengan adanya penelitian ini, penulis berharap agar masyarakat dapat mengkaji lebih banyak penelitian yang serupa, baik dengan korpus, kerangka teori, ataupun pisau analisis yang berbeda, guna memperoleh temuan-temuan baru yang lebih menarik. Penelitian yang disarankan adalah kajian tentang tract dalam peristiwa gerakan rompi kuning (gilets jaunes) yang terjadi di Prancis bahkan hingga negara-negara lainnya pada saat ini, sejak November 2018. Kajian mengenai perbandingan antara tract pada peristiwa tersebut dan tract Mai 68 yang juga menggunakan tract sebagai salah satu media menghimpun massa menarik dilakukan, tetapi dengan alasan, konteks (gilets jaunes: ekonomi) dan kondisi penyebaran tract yang berbeda (penggunaan internet dan media sosial yang massif pada masa kini) dengan Mai 68. 


\section{DAFTAR PUSTAKA}

4- 5 - 6 février 2019 - blocage national et appel à la grève générale. (2019, February 06). Diakses dari https://giletsjaunestoulouse.fr/2019/0 2/04/4-5-6-fevrier-2019-blocagenational-et-appel-a-la-grevegenerale/

Après un acte 16 peu mobilisateur, les gilets jaunes misent sur un regain le 16 mars (2019,3 Maret) L'Express. Diakses dari https://www.lexpress.fr/actualite/soci ete/apres-un-acte-16-peumobilisateur-les-gilets-jaunesmisent-sur-un-regain-le-16mars_2064933.html

Aprilianty, E. T. (2015). Analisis Aspek Bentuk Kala Lampau Bahasa Prancis Dalam Novel Le Petit Prince. Jurnal Ilmiah Mahasiswa FIB, 2(9).

Arsiyana, M., \& Widodo, P. (2017). Urutan Dan Bentuk Konstituen Klausa Bahasa Prancis Dan Bahasa Indonesia. Diksi, 25(2).

Cohen, É. (2008). L'ombre portée de Mai 68 en politique. Vingtième Siècle. Revue d'histoire, (2), 19-28.

Contamin, J. (2008). le tract, à quoi bon?. Vacarme, 45,(4), 68-71. doi:10.3917/vaca.045.0068

Doucet, I. (2019). Mai 68: L'architecture aussi!.

Duval, G. (2018). Gilets jaunes : les raisons de la colère. Alternatives Économiques, 385(12), 10-10. https://www.cairn.info/magazinealternatives-economiques-2018-12page-10.htm.

Fourquet, J., \& Manternach, S. (2018). Les" gilets jaunes": révélateur fluorescent des fractures françaises.

Guilhaumou, J. (2010)s. Mémoires d'un étudiant en mai 1968 : Le flux des manifestations et le protagoniste de l'événement. $L e$

Mouvement
Social, (233), 165-181. Diakses dari http://www.jstor.org/stable/40959671 Ismoyo, P. (2017). Islamofobia Di Prancis: Diskriminasi Perempuan Muslim Maghribi. Cakrawala, 5(2).

Retrieved from https://ejournal.uksw.edu/cakrawala/ article/view/667

Karim, K., Maknun, T., \& Abbas, A. (2019). Praanggapan Dalam Pamflet Sosialisasi Pelestarian Lingkungan Di Kabupaten Wakatobi. Jurnal Ilmu Budaya, 7(2), 241-247.

Le Querler, N. (1994). Précis de syntaxe française. Caen: Presses Universitaires de Caen

Liu, Y., \& O'Halloran, K. L. (2009). Intersemiotic texture: Analyzing cohesive devices between language and images. Social Semiotics, 19(4), 367-388.

OpenEdition. (2017). Tracts Printemps 1968. Diakses 16 Maret 2018 dari https://chsprod.hypotheses.org/jean -rene-chauvin-parcours-dunmilitant/les-annees-68-etapres/tracts-printemps-1968

Panduan, "Comment rediger un tract". Diakses 11 Februari 2018, dari http://www.cnt-f.org/59-62/wpcontent/uploads/comment-redigerun-tract.pdf

Qui paye les tracts des gilets jaunes ? (2018,12 November), France Bleu. Diakses dari https://www.francebleu.fr/infos/econ omie-social/mouvement-des-giletsjaunes-syndicats-partis-qui-soutientla-mobilisation-du-17-novembre1542129384

Ratna, R. (2016). Penggunaan Konjungsi Bahasa Prancis Pada Teks Berita Di Koran Le Monde. Jurnal Barista, 3(2), 141-157. 


\section{2 | JURNAL ILMU BUDAYA}

Rossari, C. (2018). The representation of modal meaning of French sentence adverbs in a qualitative and quantitative approach.

Sejatmiko, B. (2013). Revolusi «Gerakan Mahasiswa Prancis Mei 1968» dan Pengaruhnya di Bidang Pendidikan (Universitas) (Doctoral Dissertation, Universitas Negeri Jakarta).

Service de l'Histoire de la France, B. (1987). Les Tracts de Mai 1968. Paris: IDC Publisher

Syndicaliste Révolutionnaire, C. (2008). Tracts originaux de Mai 1968 à Rennes. Diakses 20 Februari 2018 dari

http://syndicaliste.phpnet.org/spip.ph p?article 323

Tamba, N., \& Laksman-Huntley, M. (2019). Les Structures des Phrases dans Les Tracts de Mai 1968. Les Actes De La Conférence Internationale Sur Le Français 2018 (Le Français: Réflexion Sur Les Défis Mondiaux),66-74.

Thompson, I. (2016). Tract - "The organisations of the U.N.E.F, U.G.E, the S.N.E.Sup, the C.G.T, the C.F.D.T and the F.E.N. make the following call :” (12 May 1968 UNEF, SNESup, CGT, CFDT, FEN). Diakses 14 Maret 2018 dari https://mai68inenglish.com/category/ cfdt/

Žižek, S. (2018). Provocations: The 1968 revolution and our own. World Policy Journal 35(2), 124-129. https://www.muse.jhu.edu/article/70 1274.

Zouadi, S. (2017). La combinatoire des verbes d'émotion exprimant la colère et l'admiration en français et en arabe (analyse fonctionnelle). Synergies Pologne, (14).

\begin{tabular}{|c|c|c|}
\hline & \multicolumn{2}{|r|}{ Titre } \\
\hline $\begin{array}{l}\text { Tract } \\
1\end{array}$ & \multicolumn{2}{|l|}{$\begin{array}{l}\text { Kalimat Tunggal : } \\
\text { Pour les libertés, halte à la répression! }\end{array}$} \\
\hline \multirow[t]{3}{*}{$\begin{array}{l}\text { Tract } \\
2\end{array}$} & \multicolumn{2}{|c|}{$\begin{array}{l}\text { Kalimat Tunggal: } \\
\text { Les organisations de l'U.N.E.F.U.G.E, le S.N.E.Sup, le C.G.T, le C.F.D.T, le F.E.N faites l'appel suivant }\end{array}$} \\
\hline & \multicolumn{2}{|c|}{ Intertitres et Les Paragraphes } \\
\hline & Masalah & Panggilan Gerakan \\
\hline $\begin{array}{l}\text { Tract } \\
1\end{array}$ & $\begin{array}{l}\text { Kalimat Tunggal : } \\
\text { 1. Le sang des étudiants a coulé à paris. } \\
\text { Kalimat Majemuk : } \\
\text { 1. Cette violence volontaire, aussi brutale } \\
\text { qu'injuste, du pouvoir, qui a pour }\end{array}$ & $\begin{array}{l}\text { Kalimat Tunggal : } \\
\text { 1. Dans l'unité, } \\
\text { Toutes les organisations syndicales appellent à } \\
\text { la grève générale: } \\
\quad \text { - pour la libération des étudiants emprisonnes, et }\end{array}$ \\
\hline
\end{tabular}




\begin{tabular}{|c|c|c|}
\hline & $\begin{array}{l}\text { but d'écraser les revendications, exige une } \\
\text { riposte immédiate. (Subordinatif) }\end{array}$ & $\begin{array}{l}\text { l'amnistie; } \\
\text { - } \quad \text { pour l'évacuation des forces de police du Quartier } \\
\text { Latin; } \\
\text { - pour la réouverture des facultés; } \\
\text { - } \quad \text { contre la régression sociale; } \\
\text { - pour les revendications des travailleurs, } \\
\text { 2.Rassemblement Lundi } 13 \text { Mai 1968, au Champ de Mars, à } 16 \\
\text { heures. }\end{array}$ \\
\hline $\begin{array}{l}\text { Tract } \\
2\end{array}$ & 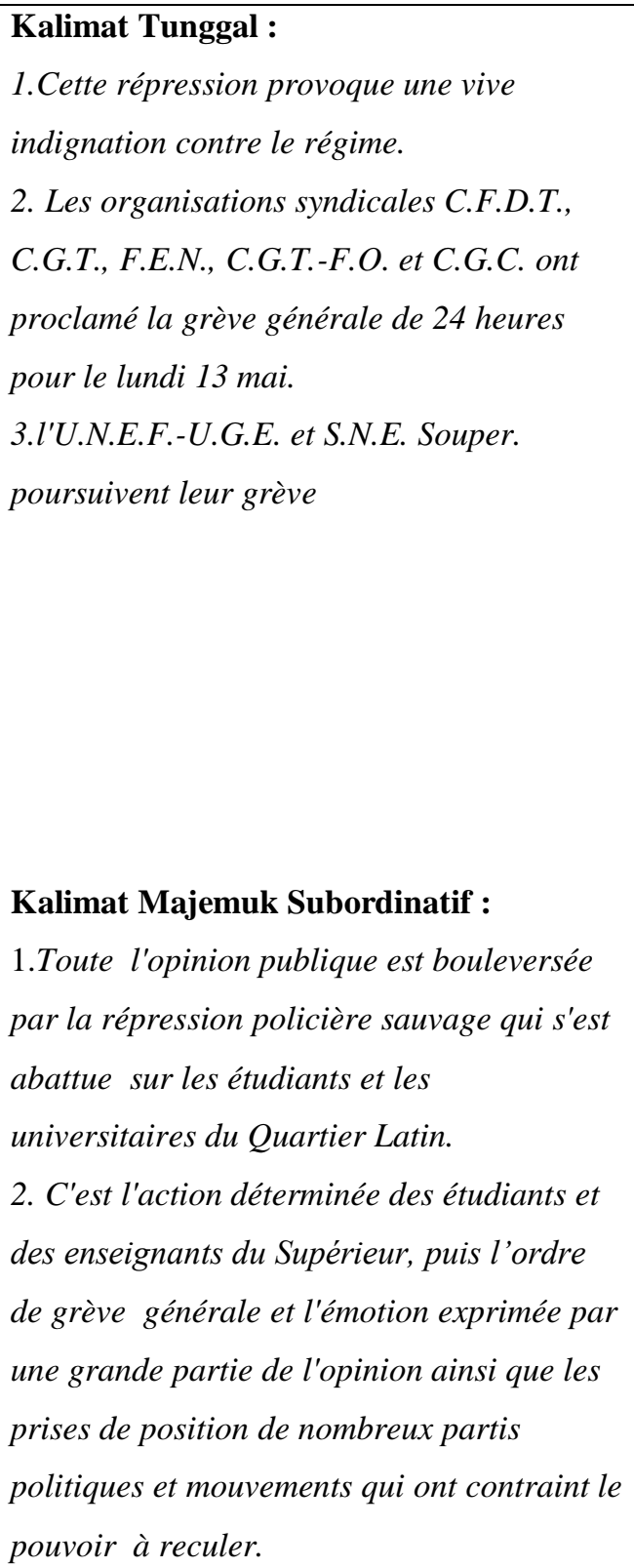 & 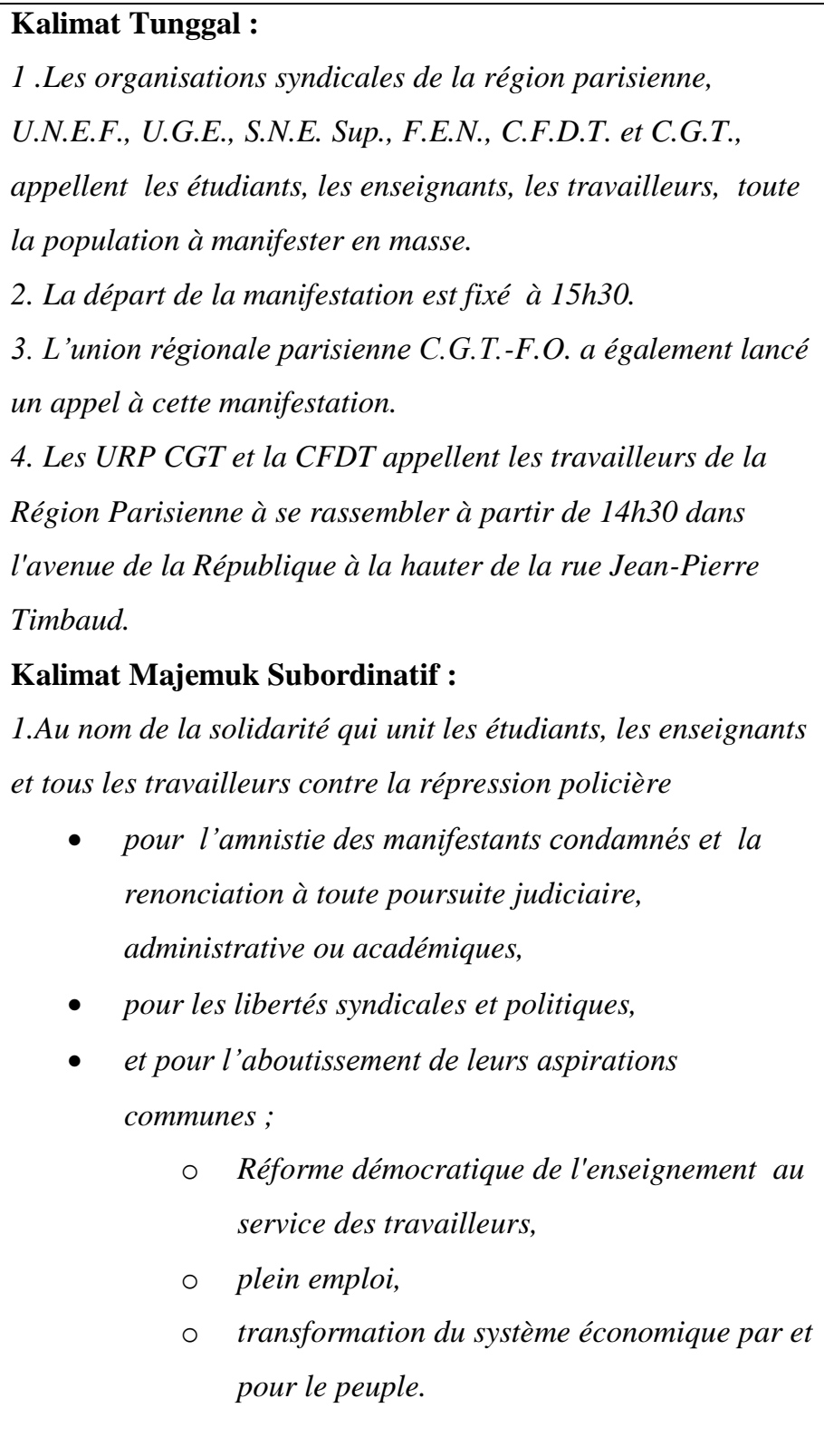 \\
\hline
\end{tabular}




\section{4 | JURNAL ILMU BUDAYA}

Volume 8, Nomor 1, Juni 2020

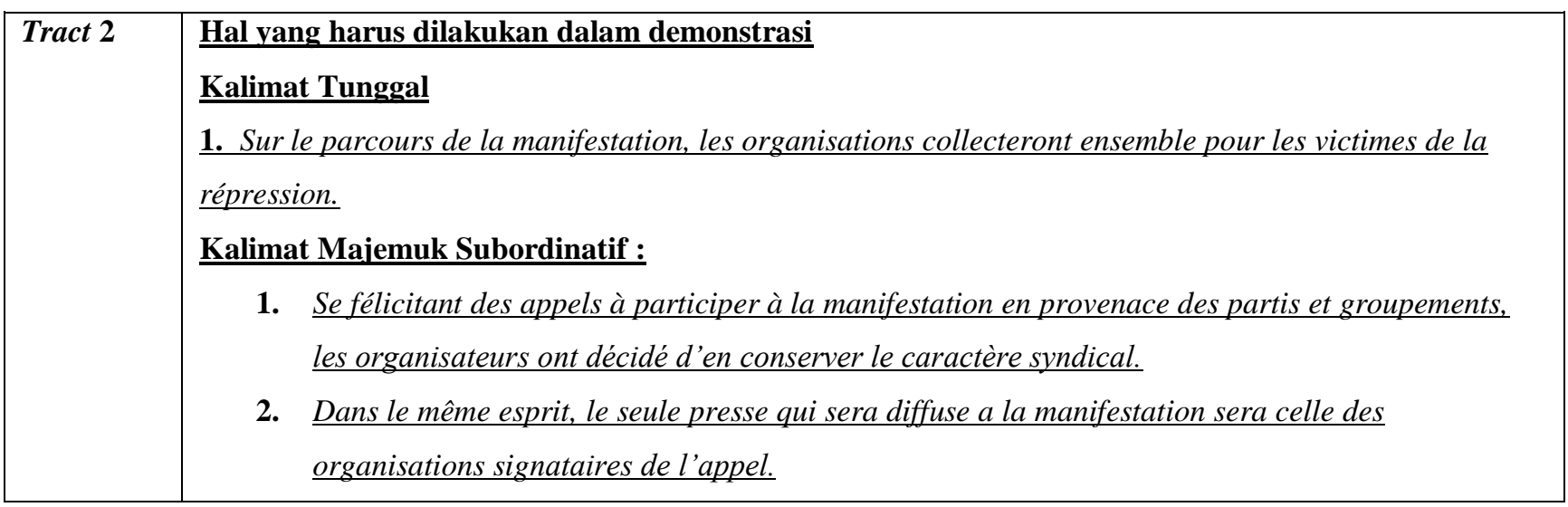

